\title{
Downregulation of IncRNA PVT1 inhibits proliferation and migration of mesothelioma cells by targeting FOXM1
}

\author{
YUTARO FUJII, VISHWA JEET AMATYA, KEI KUSHITANI, RUI SUZUKI, \\ YUICHIRO KAI, TAKAHIRO KAMBARA and YUKIO TAKESHIMA \\ Department of Pathology, Graduate School of Biomedical and Health Sciences, \\ Hiroshima University, Hiroshima 734-8551, Japan
}

Received August 13, 2021; Accepted October 12, 2021

DOI: $10.3892 /$ or.2021.8238

\begin{abstract}
Malignant mesothelioma is a highly aggressive tumor, and an effective strategy for its treatment is not yet available. Long non-coding RNAs (IncRNAs) have been reported to be associated with various biological processes, including the regulation of gene expression of cancer-related pathways. Among various IncRNAs, plasmacytoma variant translocation $1(P V T 1)$ acts as a tumor promoter in several human cancers, but its mechanism of action has not yet been elucidated. Increased PVT1 expression was identified in ACC-MESO-1, ACC-MESO-4, CRL-5915, and CRL-5946 mesothelioma cell lines. PVT1 expression was investigated in mesothelioma cell lines by reverse transcription-quantitative polymerase chain reaction and its functional analysis by cell proliferation, cell cycle, cell migration, and cell invasion assays, as well as western blot analysis of downstream target genes. Knockdown of PVT1 expression in these cell lines by small interfering RNA transfection resulted in decreased cell proliferation and migration and increased the proportion of cells in the $\mathrm{G} 2 / \mathrm{M}$ phase. The results of reverse transcription-quantitative polymerase chain reaction analysis revealed that PVT1 knockdown in mesothelioma cell lines caused the downregulation of Forkhead box M1 (FOXM1) expression, while the results of western blot analysis revealed that this knockdown reduced $F O X M I$ expression at the protein level. In addition, combined knockdown of $P V T 1$ and FOXM1 decreased the proliferation of mesothelioma cell lines. In conclusion, $P V T 1$ and FOXM1 were involved in the proliferation of cancer cells. Therefore, PVT1-FOXMI pathways may be considered as candidate targets for the treatment of malignant mesothelioma.
\end{abstract}

Correspondence to: Dr Yukio Takeshima, Department of Pathology, Graduate School of Biomedical and Health Sciences, Hiroshima University, 1-2-3 Kasumi, Minami-ku, Hiroshima 734-8551, Japan E-mail: ykotake@hiroshima-u.ac.jp

Key words: malignant mesothelioma, long non-coding RNA, plasmacytoma variant translocation 1, FOXM1, small interfering RNA

\section{Introduction}

Malignant mesothelioma is a highly aggressive tumor with poor prognosis. It arises from mesothelial cells lining the serous cavities (pleura, pericardium, peritoneum and tunica vaginalis). The incidence of mesothelioma is increasing worldwide due to previous occupational and/or environmental exposure to asbestos $(1,2)$. The incidence of malignant mesothelioma in Japan is predicted to reach a peak between 2030 and 2034. In developing countries, the incidence of this disease is predicted to increase due to the continued use of asbestos $(3,4)$. Currently available treatments have a limited effect on malignant mesothelioma management (5). Therefore, there is a need to identify feasible and effective therapeutic targets.

Non-coding RNAs are RNA molecules that are transcribed from the genome but do not encode proteins. They have been revealed to play structural and functional roles within the cell (6-10). They are primarily grouped into two classes based on transcript size: Small non-coding RNAs and long non-coding RNAs (lncRNAs) (11). Small non-coding RNAs include microRNAs (miRNAs) that function as major regulators of gene expression and complex components of cellular gene expression networks. In contrast to miRNAs, lncRNAs are a class of RNA transcripts that are over 200 nucleotides in length (12). IncRNAs have been associated with various biological processes, including epigenetics, alternative splicing, and nuclear import; additionally, they function as precursors of small non-coding RNAs, and regulators of mRNA decay (13-15). Dysregulated lncRNA expression has been reported in numerous cancers, suggesting that lncRNAs are a newly emerging class of oncogenic and tumor-suppressor genes (16).

Plasmacytoma variant translocation $1(P V T 1)$ is an oncogenic lncRNA located at chromosomal region $8 \mathrm{q} 24$ (17). The carcinogenicity of $P V T 1$ has been identified in various human cancers, including non-small cell lung (18), leukemia (19), hepatocellular (20), colon (21), breast (22), and ovarian cancer (23). Non-coding RNA expression data from Human Transcriptome 2.0 GeneChip Array analysis performed in our previous study revealed increased PVT1 expression in epithelioid mesothelioma and lung adenocarcinoma (24). In the present study, the biological function of PVT1 in mesothelioma was elucidated. 


\section{Materials and methods}

PVT1 expression database. Affymetrix mRNA expression subset data were obtained from the Cancer Cell Line Encyclopedia (CCLE) website (data created from https://www. broadinstitute.org/ccle/ on December 7, 2019). The CCLE project dataset is a compilation of gene expression data from human cancer cell lines (25).

Mesothelioma cell lines. ACC-MESO-1 (Expasy ID: CV CL_5113) and ACC-MESO-4 (Expasy ID: CVCL_5114) mesothelioma cell lines were purchased from RIKEN BioResource Research Center (Tsukuba, Japan), and NCI-H2052 (CRL-5915) and NCI-H2452 (CRL-5946) mesothelioma cell lines were purchased from the American Type Culture Collection (ATCC). In addition, two lung adenocarcinoma cell lines, A549 and PC9, purchased from the European Collection of Authenticated Cell Cultures, were also used to confirm PVTl expression in lung adenocarcinoma. Cells were cultured in Roswell Park Memorial Institute-1640 (RPMI-1640) medium supplemented with $1 \%$ kanamycin, $1 \%$ amphotericin $\mathrm{B}$, and $10 \%$ fetal bovine serum (FBS; all from Thermo Fisher Scientific, Inc.). Cells were maintained in culture dishes at $37^{\circ} \mathrm{C}$ in a humidified incubator supplied with $5 \% \mathrm{CO}_{2}$.

Transfection of mesothelioma cells. PVT1 small interfering (si)RNA (Lincode Human PVT1 siRNA - SMARTpool; cat. no. R-029357-00-0005) and its negative control (NC) siRNA (Lincode Non-targeting Pool; cat. no. D-001320-10-05) were purchased from GE Healthcare Dharmacon, Inc. Forkhead box M1 (FOXM1) siRNA (FOXM1 Silencer SelectPre-designed siRNA; cat.no. 4427037 ID\# s5248) and its NC siRNA (Silencer Select Negative Control No. siRNA; cat. no. 4390843) were purchased from Thermo Fisher Scientific, Inc. Cells cultured until attaining 70-80\% confluency, were transfected with $50 \mathrm{nM}$ of $P V T I / \mathrm{NC}$ siRNA, $25 \mathrm{nM}$ of $F O X M I / \mathrm{NC}$ siRNA, or both, using Lipofectamine RNAiMAX (Thermo Fisher Scientific, Inc.) in Opti-Mem Reduced Serum Medium (Thermo Fisher Scientific, Inc.) at $37^{\circ} \mathrm{C}$ in a humidified incubator supplied with $5 \% \mathrm{CO}_{2}$ according to the manufacturer's recommended protocols. The images of morphological change of the transfected mesothelioma cells were captured at 0 and $72 \mathrm{~h}$ using a CKX53 inverted light microscope with a DP21 digital camera (Olympus Corporation).

Reverse transcription-quantitative polymerase chain reaction (RT-qPCR). Mesothelioma cell lines $\left(3 \times 10^{5}\right.$ cells) were transfected with $15 \mathrm{pmol}$ of $P V T I / \mathrm{NC}$ siRNA or $7.5 \mathrm{pmol}$ of $F O X M 1 / \mathrm{NC}$ siRNA in 6-well plates at $37^{\circ} \mathrm{C}$ in a humidified incubator supplied with $5 \% \mathrm{CO}_{2}$ for $72 \mathrm{~h}$. RNA was extracted from the cells using Maxwell ${ }^{\circledR}$ RSC simplyRNA Cells Kit and Maxwell ${ }^{\circledR}$ RSC Instrument (both from Promega Corporation) according to the manufacturer's protocols. The extracted RNA was reverse-transcribed with SuperScript IV VILO Master Mix (Thermo Fisher Scientific, Inc.) and amplified using Power Up SYBR Green Master Mix (Thermo Fisher Scientific, Inc.) on an AriaMx Real-Time PCR System (Agilent Technologies, Inc.) according to the manufacturer's recommended protocols. In brief, qPCR was performed with initial denaturation at $95^{\circ} \mathrm{C}$ for 10 min followed by 40 cycles of denaturation at $95^{\circ} \mathrm{C}$ for $15 \mathrm{sec}$ and annealing and elongation at $60^{\circ} \mathrm{C}$ for $1 \mathrm{~min}$, and a dissociation curve condition from $95^{\circ} \mathrm{C}$ to $60^{\circ} \mathrm{C}$. Relative expression levels were calculated using the comparative $2-^{\Delta \Delta \mathrm{Cq}}$ method (26). Expression levels were normalized against those of glyceraldehyde 3-phosphate dehydrogenase (GAPDH). The primer sequences used for RT-qPCR were as follows: $P V T 1$ forward, 5'-TGAGAACTGTCCTTACGT GACC-3' and reverse, 5'-AGAGCACCAAGACTGGCTCT-3'; FOXM1 forward, 5'-GGAGCAGCGACAGGTTAAGG-3' and reverse, 5'-GTTGATGGCGAATTGTATCATGG-3'; and GAPDH forward, 5'-ACAACTTTGGTATCGTGGAAGG-3' and reverse, 5'-GCCATCACGCCACAGTTTC-3'.

Cell proliferation assay. Mesothelioma cell lines $\left(3 \times 10^{3}\right.$ cells $)$ were incubated with $1 \mathrm{pmol} P V T 1 / \mathrm{NC}$ siRNA or $0.5 \mathrm{pmol}$ FOXM1/NC siRNA in $96-$ well plates at $37^{\circ} \mathrm{C}$ in a humidified incubator supplied with $5 \% \mathrm{CO}_{2}$ for 3 days. The proliferation rate was determined at 24,48 and $72 \mathrm{~h}$ using $100 \mu \mathrm{l}$ of $2 \mathrm{X}$ Cell Titer-Glo 2.0 reagent (Promega Corporation), which assesses the number of viable cells relative to the ATP level, with a GloMax Explorer microplate reader (Promega Corporation) according to the manufacturer's protocols.

Cell cycle assay. Mesothelioma cell lines ( $1 \times 10^{5}$ cells) were transfected with 5 pmol $P V T I / \mathrm{NC}$ siRNA in 24-well plates for 3 days, and subsequently the cells were collected after trypsinization and fixed in $70 \%$ ethanol in $15-\mathrm{ml}$ centrifuge tubes at room temperature for $3 \mathrm{~h}$. After ethanol removal, the cells were stained with $200 \mathrm{ml}$ of Guava Cell Cycle Reagent (Luminex Corporation) at room temperature shielding away from the light for $30 \mathrm{~min}$. The reagent containing propidium iodide discriminates the cells at different stages of the cell cycle by labeling cellular DNA. The labeling signal intensity was evaluated using a Guava EasyCyte Mini flow cytometer (Guava Technologies) according to the manufacturer's protocols. Analysis of raw data was performed with FCS express 5.0 (De Novo Software).

Wound healing assay. The migration ability of all four mesothelioma cells was analyzed using a wound scratch assay. Serum starved mesothelioma cell lines grown to $80 \%$ confluence were incubated overnight with 5 pmol $P V T I / \mathrm{NC}$ siRNA in collagen-coated 24 -well plates at $37^{\circ} \mathrm{C}$ in a humidified incubator supplied with $5 \% \mathrm{CO}_{2}$. Wounds were created by scratching the cells with 1-ml micropipette tips. The wells were washed twice to remove floating cells. Images of the gap area (wound) were captured every $24 \mathrm{~h}$ (for ACC-MESO-1 every $12 \mathrm{~h}$ ) using a CKX53 inverted light microscope equipped with a DP21 digital camera (Olympus Corporation), and the gap area was further analyzed using T Scratch software version 1.0 downloaded from https://github.com/cselab/TScratch (27).

Cell invasion assay. BD FluroBlok culture inserts containing $8-\mu \mathrm{m}$ pores (BD Biosciences) were coated with $100 \mu \mathrm{l}$ of 10X diluted Geltrex Matrigel (Thermo Fisher Scientific, Inc.) at $37^{\circ} \mathrm{C}$ in a humidified incubator supplied with $5 \% \mathrm{CO}_{2}$ for $3 \mathrm{~h}$. Mesothelioma cell lines ( $3 \times 10^{4}$ ACC-MESO- 1 cells, and $5 \times 10^{4}$ ACC-MESO-4, CRL-5915, CRL-5946 cells) were incubated with 3 pmol siRNA in $500 \mu 1$ RPMI-1640 medium (without FBS) in the upper chamber of culture inserts and $750 \mu 1$ RPMI-1640 

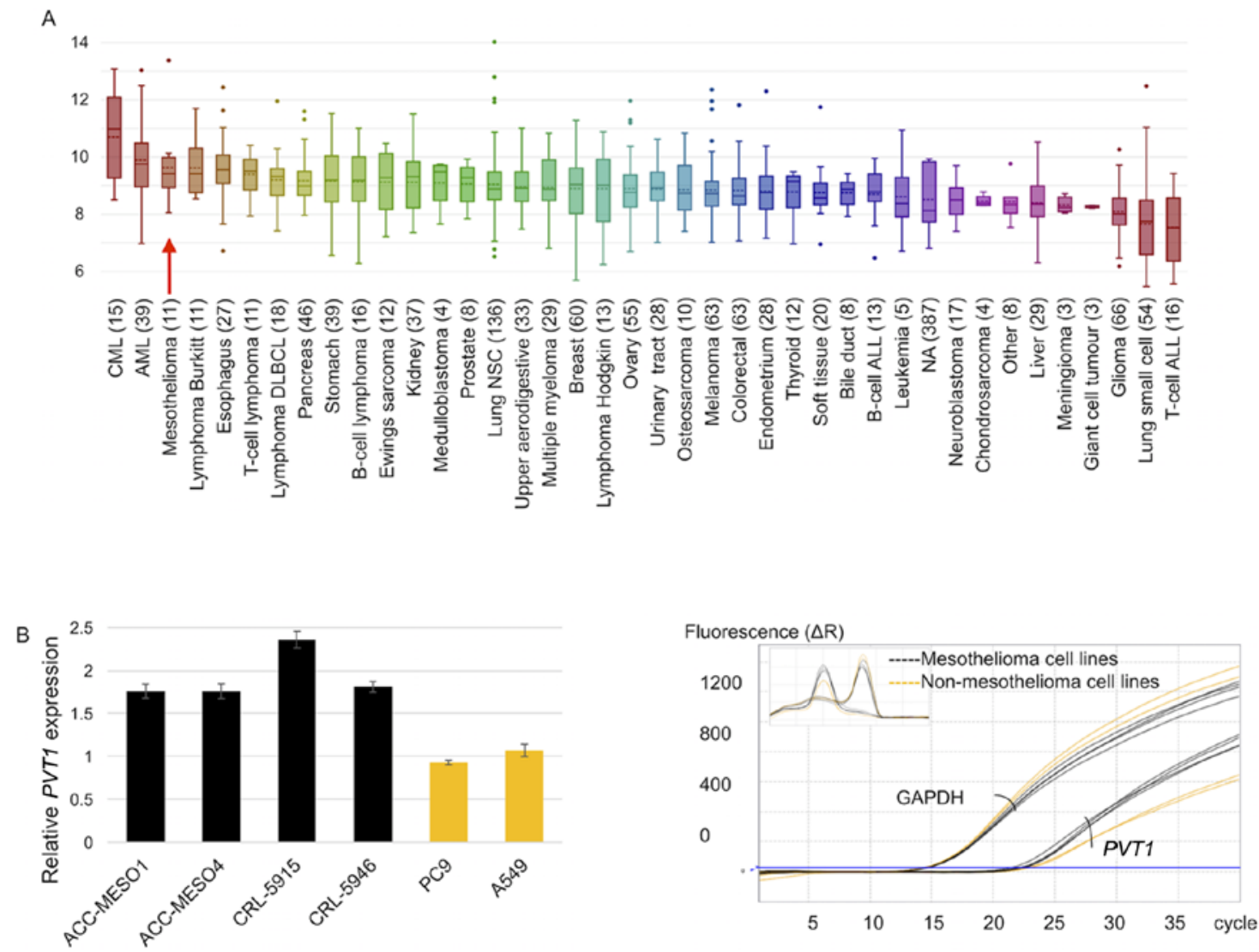

Figure 1. (A) Box-whisker plot demonstrating PVT1 expression in various human cancers from the Cancer Cell Line Encyclopedia project. Mesothelioma cell lines are indicated by the red arrow. (B) Left panel, relative expression of long non-coding RNA PVT1 as determined by reverse transcription-quantitative PCR in mesothelioma and lung adenocarcinoma cell lines. Right panel, amplification and dissociation curves of $P V T 1$ expression. $P V T 1$, plasmacytoma variant translocation 1.

medium containing 5\% FBS in the lower chamber of culture inserts according to the manufacturer's protocols. Cells were incubated at $37^{\circ} \mathrm{C}$ in a humidified incubator supplied with $5 \% \mathrm{CO}_{2}$ for $72 \mathrm{~h}$ (48 h for ACC-MESO-1 cells), and invading cells were stained with addition of $50 \mu \mathrm{l}$ of $1 \mu \mathrm{g} / \mathrm{ml}$ solution of Hoechst 33324 (Thermo Fisher Scientific, Inc.) at room temperature for $10 \mathrm{~min}$, and subsequently the imaged area of the insert membrane was visualized using a fluorescence microscope. The total number of invading cells was analyzed using the CellProfiler cell imaging software version 2.1.0 downloaded from https://cellprofiler.org (28).

Western blot analysis. Mesothelioma cell lines $\left(3 \times 10^{5}\right.$ cells $)$ were transfected with $15 \mathrm{pmol} P V T 1 / \mathrm{NC}$ siRNA in 6-well plates for $72 \mathrm{~h}$. Cell lysates were obtained from the cells using RIPA Lysis Buffer System (Santa Cruz Biotechnology, Inc.), and total protein was determined with Qubit ${ }^{\text {Th }}$ Protein Assay Kit using a Qubit Fluorometer (Thermo Fisher Scientific, Inc.) Total proteins $(20 \mu \mathrm{g})$ were electrophoresed on a $10 \%$ sodium dodecyl sulfate-polyacrylamide gel (SureCast Acrylamide Gel; Thermo Fisher Scientific, Inc.) at $200 \mathrm{~V}$ for $40 \mathrm{~min}$ and transferred onto polyvinylidene difluoride (PVDF) membranes using a Mini Blot Module (Thermo Fisher Scientific, Inc.) at $20 \mathrm{~V}$ for 60 min. Following blocking with $2 \%$ bovine serum albumin (Sigma Aldrich; Merck KGaA) in 1X TBS with $0.05 \%$ Tween-20 at room temperature for $1 \mathrm{~h}$, the membranes were incubated overnight at $4^{\circ} \mathrm{C}$ with primary antibodies [anti-FOXM1 rabbit monoclonal antibody (1:4,000; product no. 20459S) and an anti-GAPDH rabbit monoclonal antibody $(1: 4,000$; product no. 2118S; both from Cell Signaling Technology, Inc.)]. The membranes were then incubated with the anti-rabbit $\mathrm{IgG}$, HRP-linked secondary antibody (1:4,000; cat. no. 7074P2; Cell Signaling Technology, Inc.) at room temperature for $40 \mathrm{~min}$. The membranes were stained with ImmunoStar LD (Wako Pure Chemical Industries) at room temperature for $1 \mathrm{~min}$ and images were captured using a c-Digit Blot Scanner (LI-COR). Scanned images were analyzed by Image Studio Digits software version 5.2 (LI-COR Biosciences).

Statistical analysis. The experiments were performed at least three times in triplicate. Experimental data are expressed as the mean \pm standard deviation. The statistical significance of the difference between two groups was analyzed using unpaired Student's t-test with the default function of Microsoft Excel version 16.53 . $P<0.05$ was considered to indicate a statistically significant difference.

\section{Results}

PVT1 expression in mesothelioma and lung adenocarcinoma cell lines. PVT1 expression was high in mesothelioma and non-small cell cancers, in addition to different human cancers (Fig. 1A). RT-qPCR analysis results revealed that $P V T I$ was expressed in all four mesothelioma cell lines and two 
A

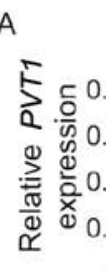

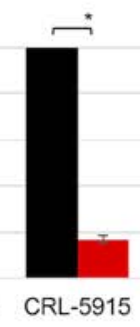

- NC SIRNA $=$ PVT1 SIRNA

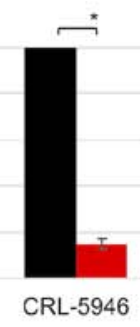

${ }^{*} \mathrm{P}<0.001$
NC siRNA

B
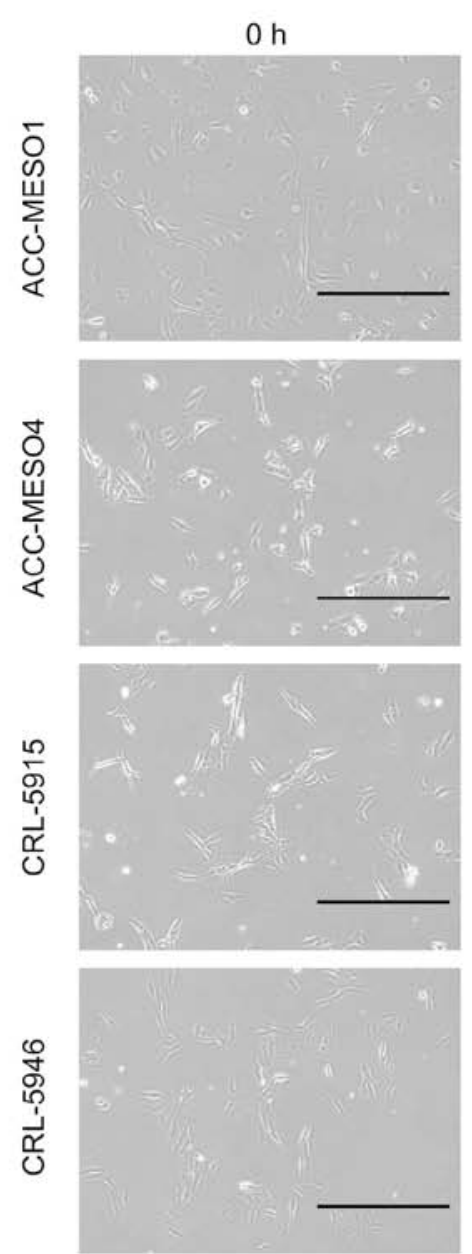

$72 \mathrm{~h}$
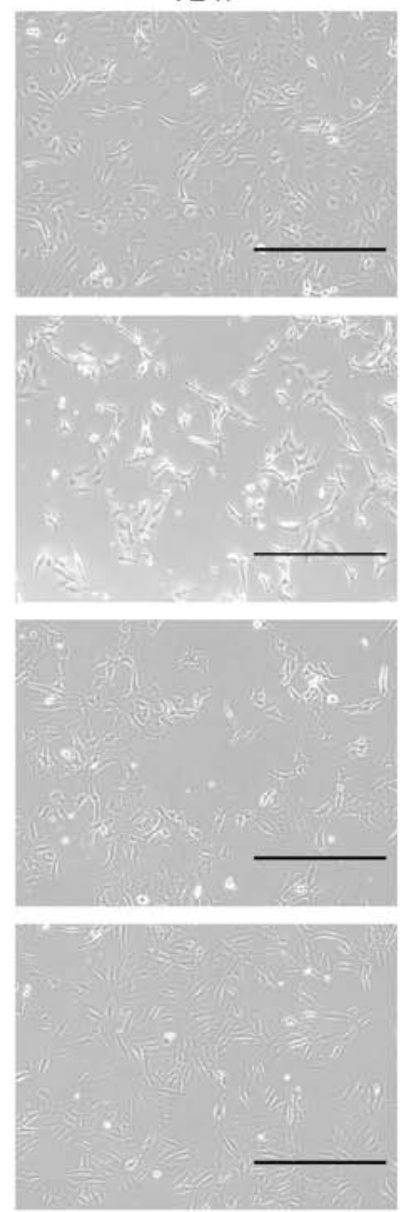

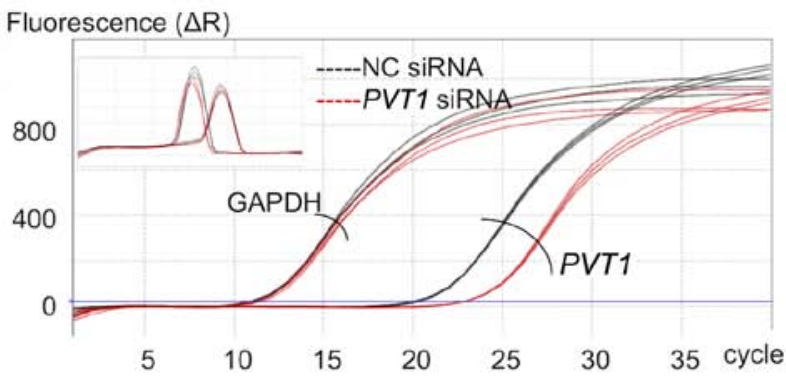

PVT1 siRNA

$\mathrm{Oh}$
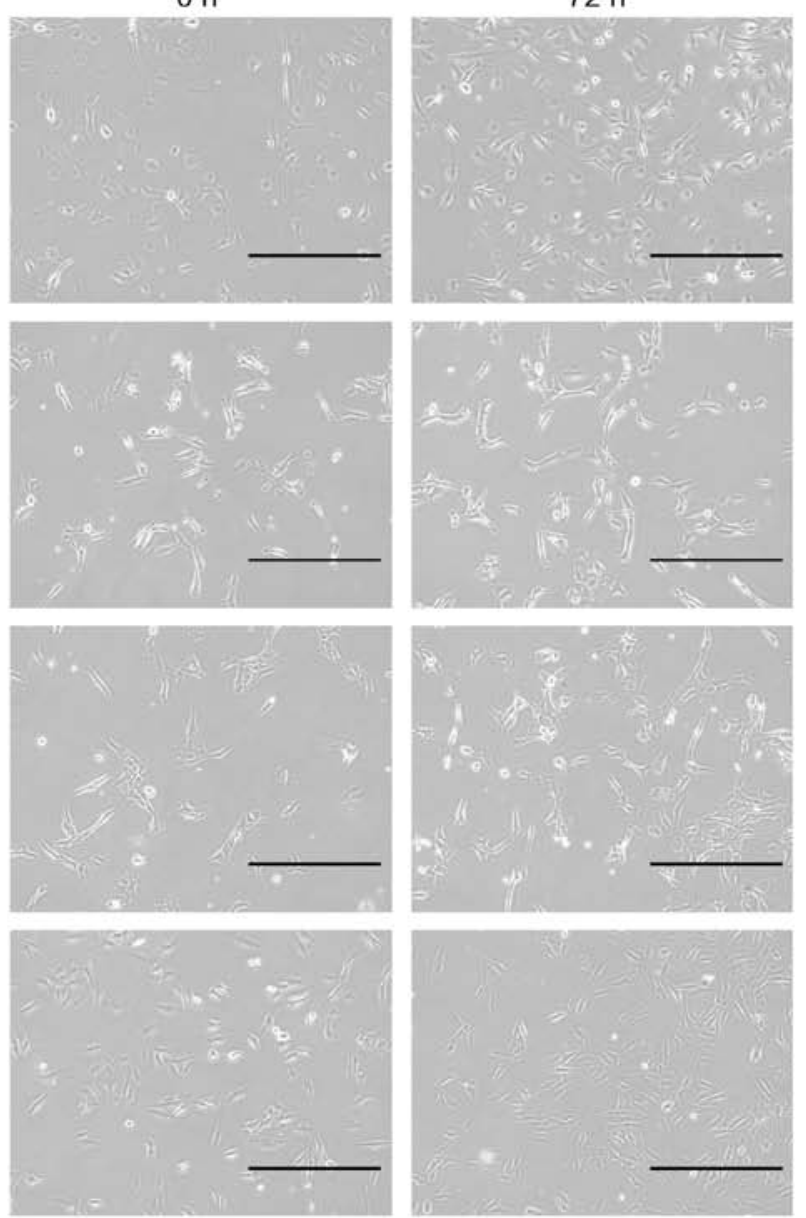

Figure 2. (A) Left panel, knockdown of long non-coding RNA PVT1 expression in siRNA-transfected mesothelioma cell lines as determined by reverse transcription-quantitative PCR. Right panel, amplification curves of PVT1 expression with dissociation curves. (B) Images demonstrating morphology of mesothelioma cell lines at 0 and $72 \mathrm{~h}$ of siRNA transfection. There were no prominent morphological changes between negative control and $P V T 1$ siRNA-transfected cells. Scale bar, $500 \mu \mathrm{m}$. PVT1, plasmacytoma variant translocation 1; siRNA, small interfering RNA; NC, negative control.

lung adenocarcinoma cell lines. Compared with the average $P V T 1$ expression in the two lung adenocarcinoma cell lines, $P V T 1$ expression was increased by 1.8-, 1.8-, 2.4-, and 1.8-fold in ACC-MESO-1, ACC-MESO-4, CRL-5915 and CRL-5946 cell lines, respectively (Fig. 1B).

PVT1 expression is reduced by siRNA transfection. PVT1 expression was downregulated by $>80 \%$ following $P V T 1$ siRNA transfection in all mesothelioma cell lines compared with that in cells transfected with NC siRNA (Fig. 2A). Morphological changes were not observed in PVTI siRNA-transfected mesothelioma cell lines compared with NC siRNA-transfected mesothelioma cell lines (Fig. 2B).

PVT1 knockdown reduces mesothelioma cell proliferation and increases the G2/M phase of the cell cycle. Knockdown of PVT1 significantly reduced the proliferation of all mesothelioma cells compared with NC siRNA-transfected cells. 
A

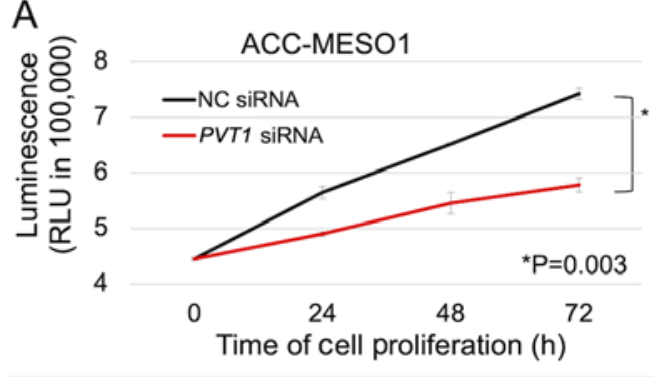

Oh $\quad 24 \mathrm{~h} \quad 48 \mathrm{~h} \quad 72 \mathrm{~h}$

NC SiRNA $\quad 3.95 \pm 0.035 .15 \pm 0.116 .01 \pm 0.026 .92 \pm 0.10$

PVT1 SiRNA $3.95 \pm 0.034 .40 \pm 0.045 .11 \pm 0.195 .33 \pm 0.13$

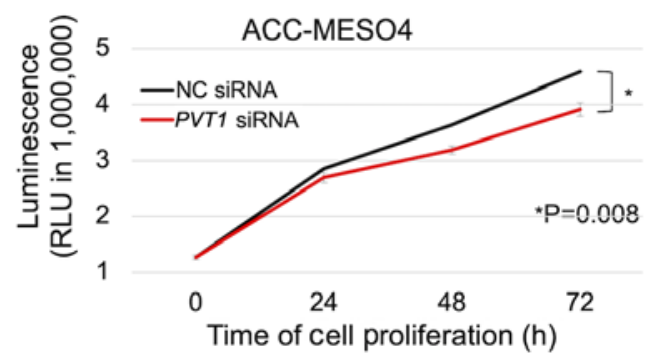

Oh $\quad 24 \mathrm{~h} \quad 48 \mathrm{~h} \quad 72 \mathrm{~h}$

NC SiRNA $\quad 1.27 \pm 0.042 .85 \pm 0.113 .63 \pm 0.054 .59 \pm 0.03$ PVT1 siRNA $1.27 \pm 0.042 .70 \pm 0.093 .19 \pm 0.073 .91 \pm 0.12$

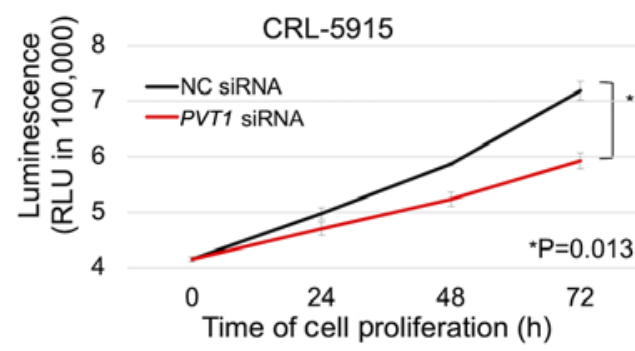

\begin{tabular}{ll|l|l|l}
\hline $0 h$ & $24 \mathrm{~h}$ & $48 \mathrm{~h}$ & $72 \mathrm{~h}$
\end{tabular}

NC siRNA $\quad 4.16 \pm 0.044 .98 \pm 0.115 .87 \pm 0.037 .19 \pm 0.17$

PVT1 siRNA $4.16 \pm 0.044 .70 \pm 0.125 .23 \pm 0.135 .93 \pm 0.14$

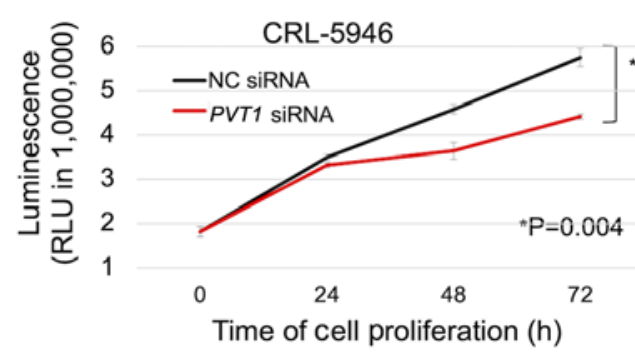

\begin{tabular}{ll|l|l|l}
\hline $0 h$ & $24 \mathrm{~h}$ & $48 \mathrm{~h}$ & $72 \mathrm{~h}$
\end{tabular}

NC SiRNA $\quad 1.82 \pm 0.123 .50 \pm 0.074 .59 \pm 0.105 .76 \pm 0.20$

PVT1 siRNA $1.82 \pm 0.123 .33 \pm 0.053 .64 \pm 0.194 .42 \pm 0.06$

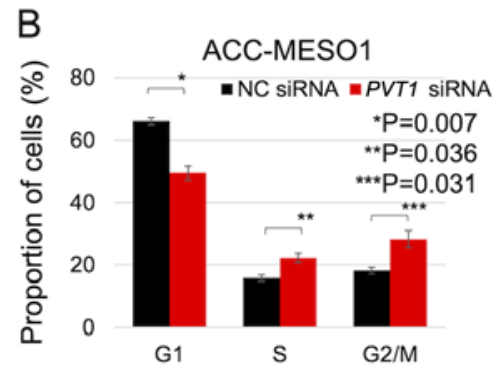

\begin{tabular}{lllll}
\hline G1 & $S$ & G2/M
\end{tabular}

$\begin{array}{llll}\text { NC SIRNA } & 66.0 \pm 1.1 & 15.8 \pm 1.0 & 18.2 \pm 1.0\end{array}$ \begin{tabular}{l|l|l|l} 
PVT1 SIRNA & $49.4 \pm 2.2$ & $22.3 \pm 1.5$ & $28.3 \pm 2.7$
\end{tabular}
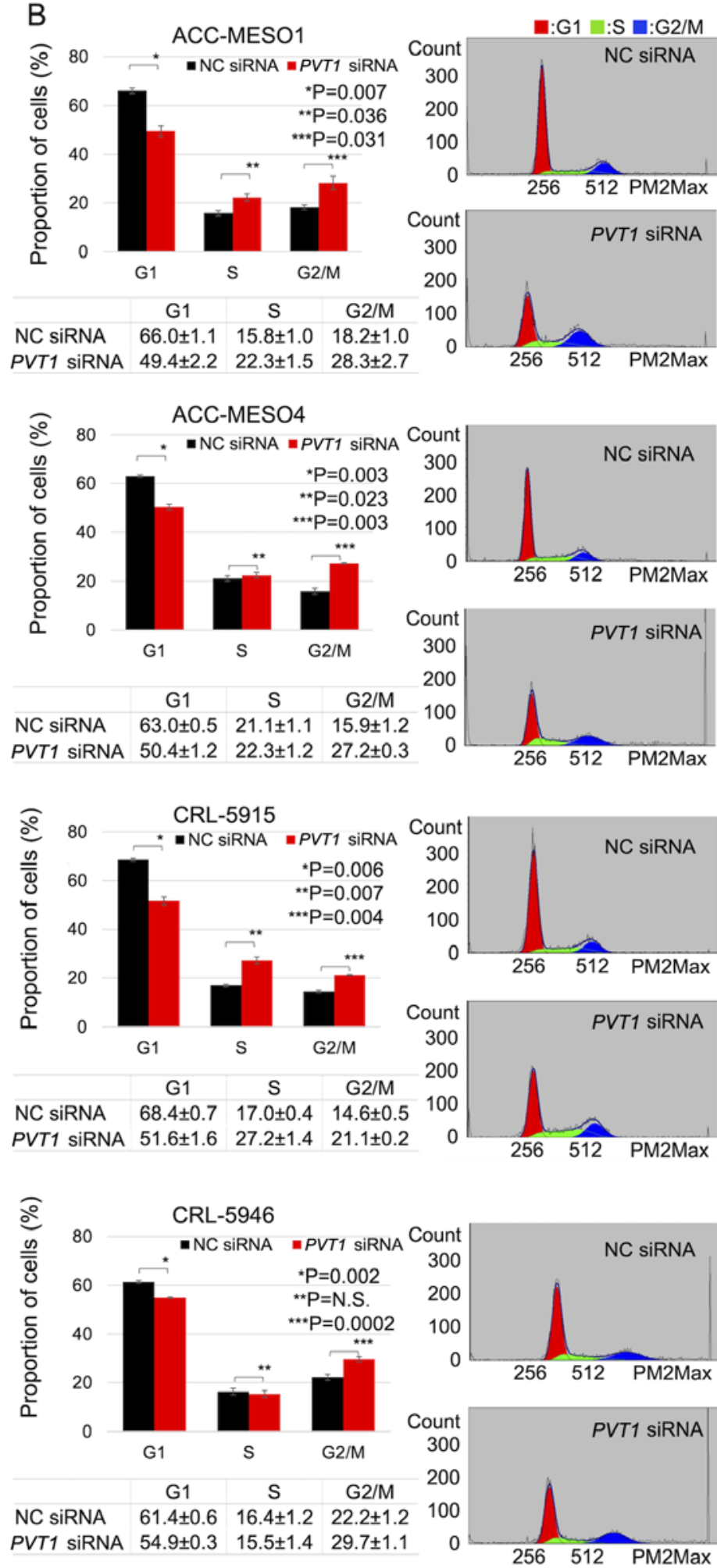

Figure 3. (A) Cell proliferation assay of mesothelioma cell lines transfected with PVT1 siRNA, and NC siRNA for three days. (B) Cell cycle analysis of four mesothelioma cell lines transfected with $P V T 1$ siRNA or NC siRNA after three days. (Images in the right panel are representative cell cycle histograms). $P V T 1$, plasmacytoma variant translocation 1; siRNA, small interfering RNA; NC, negative control

Following 3 days of treatment, the inhibition of PVT1 expression significantly reduced the viability of ACC-MESO-1 cells by $22.9 \%$, ACC-MESO-4 cells by $14.8 \%$, CRL-5915 cells by $17.6 \%$, and CRL-5946 cells by $23.3 \%$ (Fig. 3A). The proportion of cells in the $\mathrm{G} 2 / \mathrm{M}$ phase in the PVT1 siRNA-transfected mesothelioma cell lines (28.7, 27.4, 21.0 and $30.3 \%$ in ACC-MESO-1, ACC-MESO-4, CRL-5915, and CRL-5946 cell lines, respectively) was significantly higher than with the NC siRNA-transfected mesothelioma cell lines $(17.5,15.6,14.4$, and $22.8 \%)$. The proportion of cells in the G1 phase in the PVT1 siRNA-transfected mesothelioma cell lines (49.6, 50.2, 52.5 and $55.0 \%$, in 

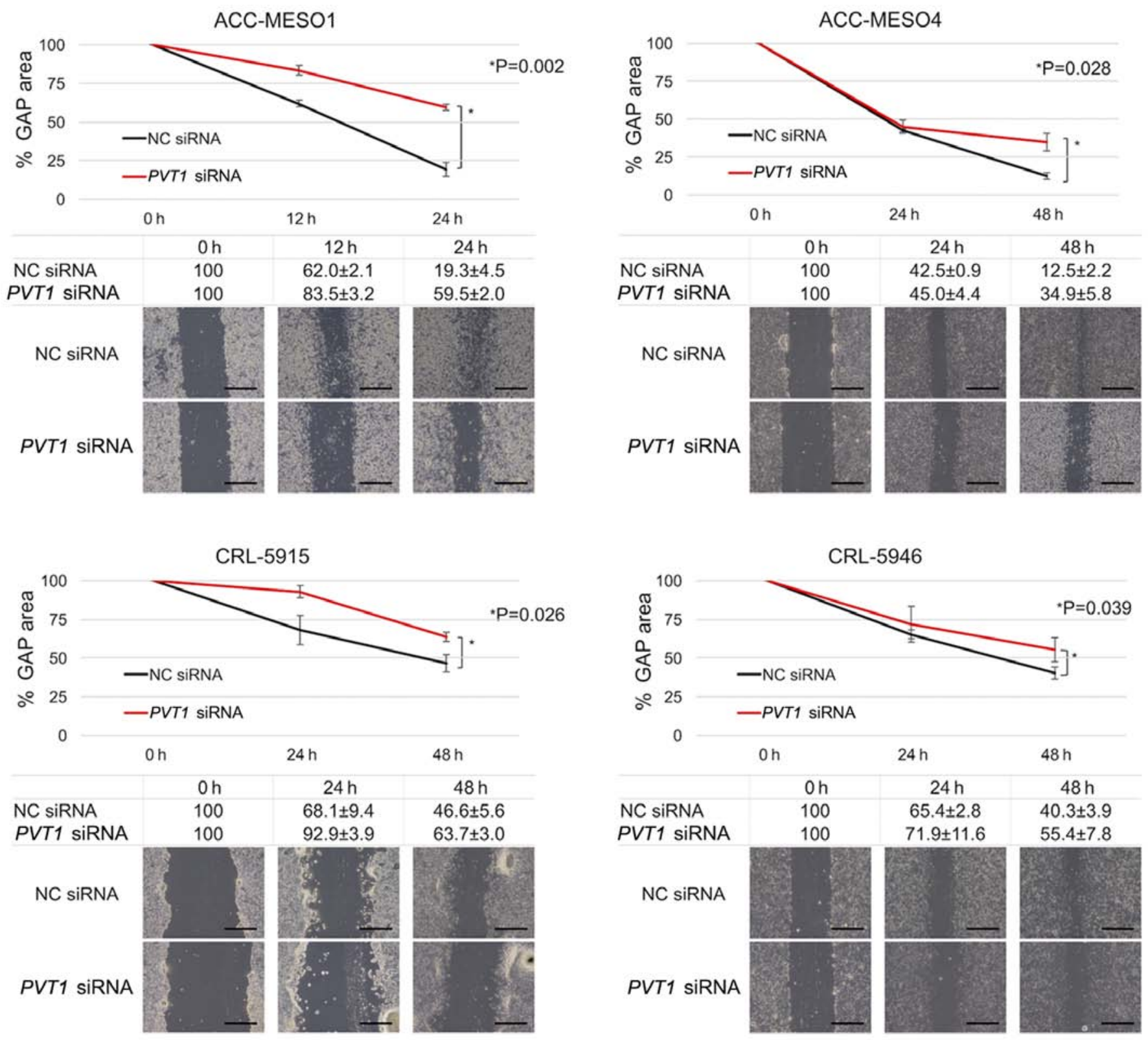

Figure 4. Migration assay of mesothelioma cells transfected with PVT1 siRNA or NC siRNA. Panel figures are representative images acquired using a microscope. Scale bar, $1 \mathrm{~mm}$. PVT1, plasmacytoma variant translocation 1; siRNA, small interfering RNA; NC, negative control.

ACC-MESO-1, ACC-MESO-4, CRL-5915, and CRL-5946 cell lines, respectively) was significantly lower than with the NC siRNA-transfected mesothelioma cell lines $(66.3,63.2$, 68.8 and 61.1\%) (Fig. 3B).

PVT1 knockdown reduces mesothelioma cell migration but not invasion. In the PVT1 siRNA-transfected cells, the gap area decreased more slowly than in the NC siRNA-transfected cell lines in all four cell lines. The migration of ACC-MESO-1 cells after $24 \mathrm{~h}$ of PVT1 knockdown was reduced by $67.5 \%$ and that of ACC-MESO-4, CRL5915, and CRL5946 cell lines after $48 \mathrm{~h}$ of PVT1 knockdown was reduced by $64.2,26.8$ and $27.3 \%$, respectively (Fig. 4). PVT1 was inhibited by siRNA, but it was not significantly associated with the invasion of all four mesothelioma cell lines (data not shown).
PVT1 knockdown downregulates FOXM1 expression. All four mesothelioma cell lines exhibited FOXM1 expression. FOXM1 mRNA expression in cells transfected with PVT1 siRNA compared with cells transfected with NC siRNA was downregulated by $77,83,84$ and $82 \%$ in ACC-MESO1, ACC-MESO4, CRL-5915, and CRL-5946 cell lines, respectively (Fig. 5A). Similarly, FOXM1 protein was downregulated by $41 \%$ in ACC-MESO- 1 cells, $35 \%$ in ACC-MESO-4 cells, $56 \%$ in CRL-5915 cells, and 55\% in CRL-5946 cells (Fig. 5B).

FOXM1 and PVT1 knockdown reduces mesothelioma cell proliferation. Transfection with either FOXM1 or PVT1 siRNA revealed a similar decrease in the proliferation of mesothelioma cells. However, combined FOXM1 and PVT1 siRNA transfection further decreased the proliferation of mesothelioma cells. Following 3 days of treatment, FOXM1 knockdown significantly 


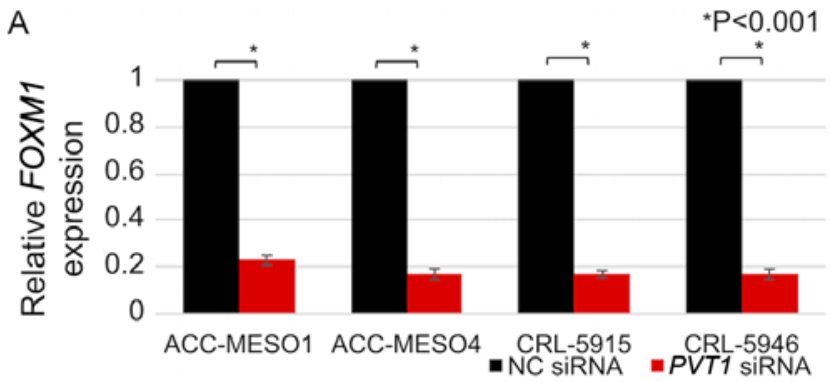

Fluorescence $(\Delta R)$

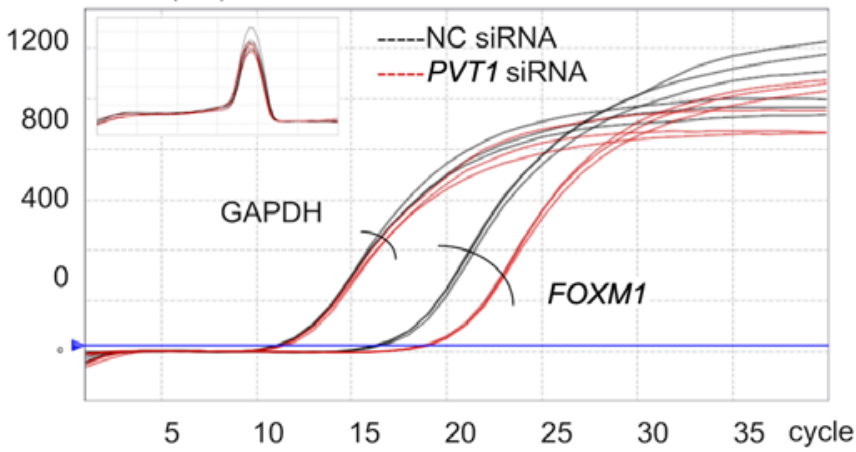

B

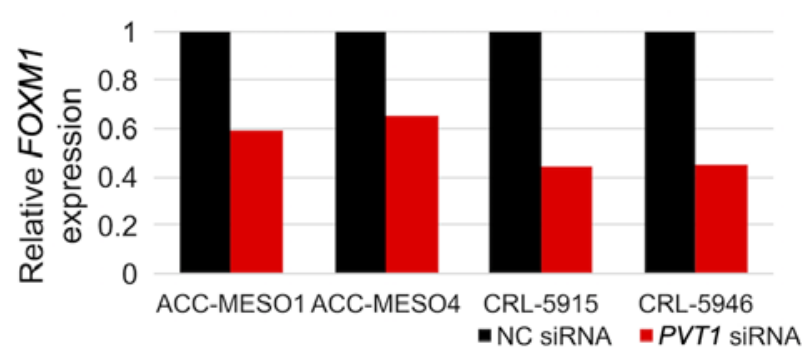

FOXM1

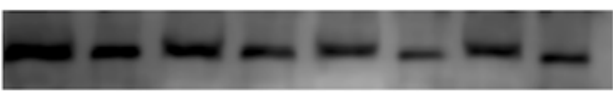

GAPDH

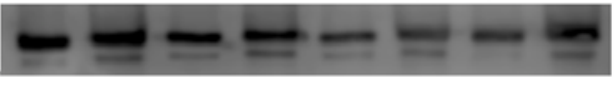

ACC-MESO1 ACC-MESO4 CRL-5915 CRL-5946

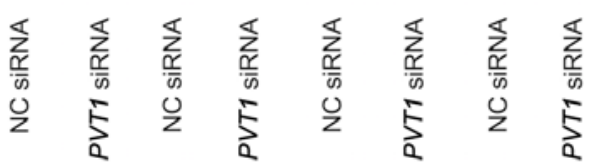

Figure 5. (A) FOXM1 expression of $P V T 1$ or NC siRNA transfection as determined by reverse transcription-quantitative PCR. The lower panel reveals amplification curves of $P V T 1$ expression with dissociation curves. (B) FOXM1 expression as determined by western blot analysis in PVT1 or NC siRNA-transfected cells. FOXM1, Forkhead box M1; PVT1, plasmacytoma variant translocation 1; siRNA, small interfering RNA; NC, negative control.

\section{ACC-MESO1}

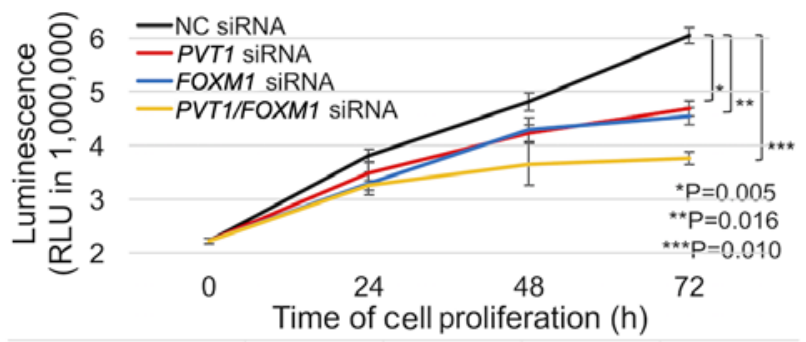

$\begin{array}{lllll}0 \mathrm{~h} & 24 \mathrm{~h} & 48 \mathrm{~h} & 72 \mathrm{~h}\end{array}$ $\begin{array}{llllll} & \text { NC siRNA } & 2.22 \pm 0.05 & 3.81 \pm 0.12 & 4.81 \pm 0.17 & 6.05 \pm 0.15\end{array}$ $\begin{array}{lllll}\text { PVT1 siRNA } & 2.22 \pm 0.05 & 3.48 \pm 0.20 & 4.22 \pm 0.16 & 4.69 \pm 0.14\end{array}$ $\begin{array}{llllll}\text { FOXM1 SIRNA } & 2.22 \pm 0.05 & 3.29 \pm 0.21 & 4.30 \pm 0.22 & 4.55 \pm 0.16\end{array}$ PVT1/FOXM1 SIRNA $2.22 \pm 0.05 \quad 3.26 \pm 0.09 \quad 3.65 \pm 0.39 \quad 3.76 \pm 0.12$

CRL-5915

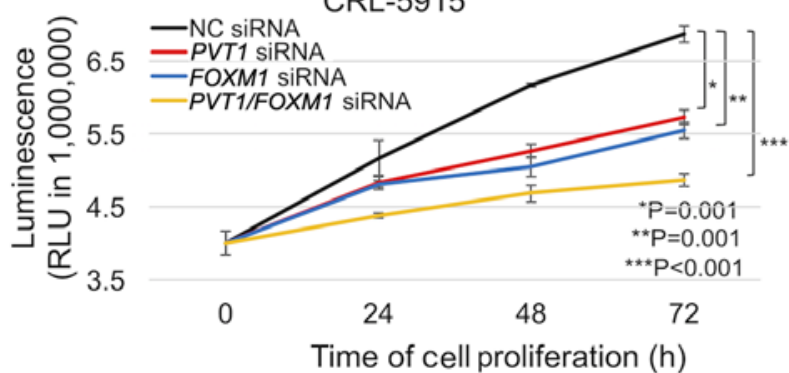

$\begin{array}{llll}0 \mathrm{~h} & 24 \mathrm{~h} & 48 \mathrm{~h} & 72 \mathrm{~h}\end{array}$

NC siRNA $\quad 4.00 \pm 0.17 \quad 5.17 \pm 0.24 \quad 6.17 \pm 0.03 \quad 6.87 \pm 0.12$ $\begin{array}{lllll}\text { PVT1 SIRNA } & 4.00 \pm 0.17 & 4.84 \pm 0.08 & 5.27 \pm 0.10 & 5.73 \pm 0.10\end{array}$ FOXM1 SIRNA $\quad 4.00 \pm 0.17 \quad 4.80 \pm 0.06 \quad 5.05 \pm 0.13 \quad 5.55 \pm 0.11$ PVT1/FOXM1 SIRNA $4.00 \pm 0.17 \quad 4.38 \pm 0.04 \quad 4.68 \pm 0.11 \quad 4.87 \pm 0.09$

\section{ACC-MESO4}

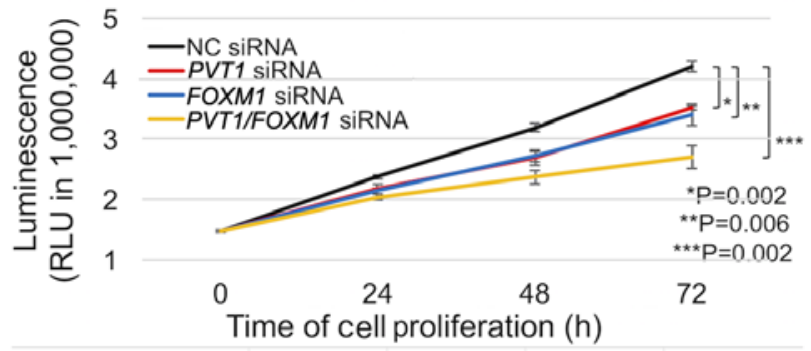

\begin{tabular}{lcccc} 
& $0 \mathrm{~h}$ & $24 \mathrm{~h}$ & $48 \mathrm{~h}$ & $72 \mathrm{~h}$ \\
\hline NC siRNA & $1.48 \pm 0.02$ & $2.37 \pm 0.03$ & $3.19 \pm 0.07$ & $4.20 \pm 0.09$
\end{tabular}

$\begin{array}{llllll}P V T 1 \text { siRNA } & 1.48 \pm 0.02 & 2.17 \pm 0.02 & 2.69 \pm 0.13 & 3.52 \pm 0.03\end{array}$ $\begin{array}{llllll}\text { FOXM1 SIRNA } & 1.48 \pm 0.02 & 2.15 \pm 0.11 & 2.71 \pm 0.09 & 3.40 \pm 0.18\end{array}$ $\begin{array}{lllll}P V T 1 / F O X M 1 \text { siRNA } & 1.48 \pm 0.02 & 2.04 \pm 0.05 & 2.37 \pm 0.11 & 2.70 \pm 0.19\end{array}$

CRL-5946

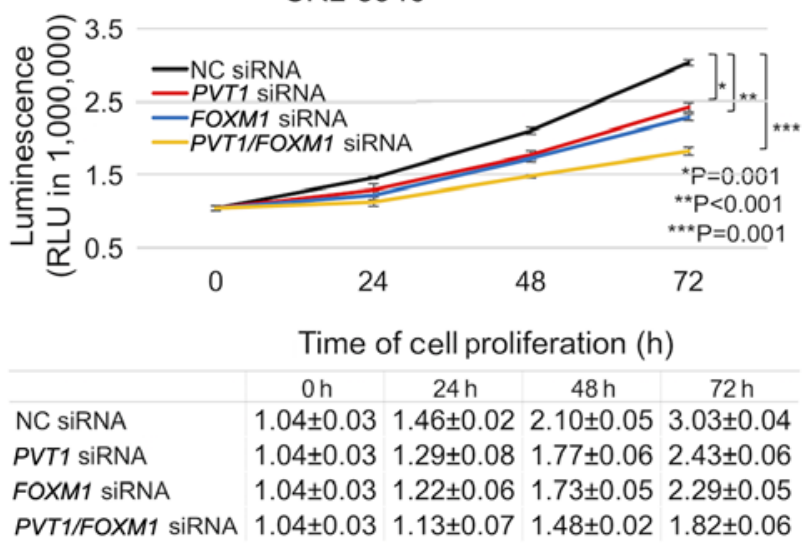

Figure 6. Cell proliferation assay of mesothelioma cell lines transfected with PVT1 siRNA, FOXM1 siRNA and combination of both siRNAs for three days. FOXM1, Forkhead box M1; PVT1, plasmacytoma variant translocation 1; siRNA, small interfering RNA; NC, negative control. 
A
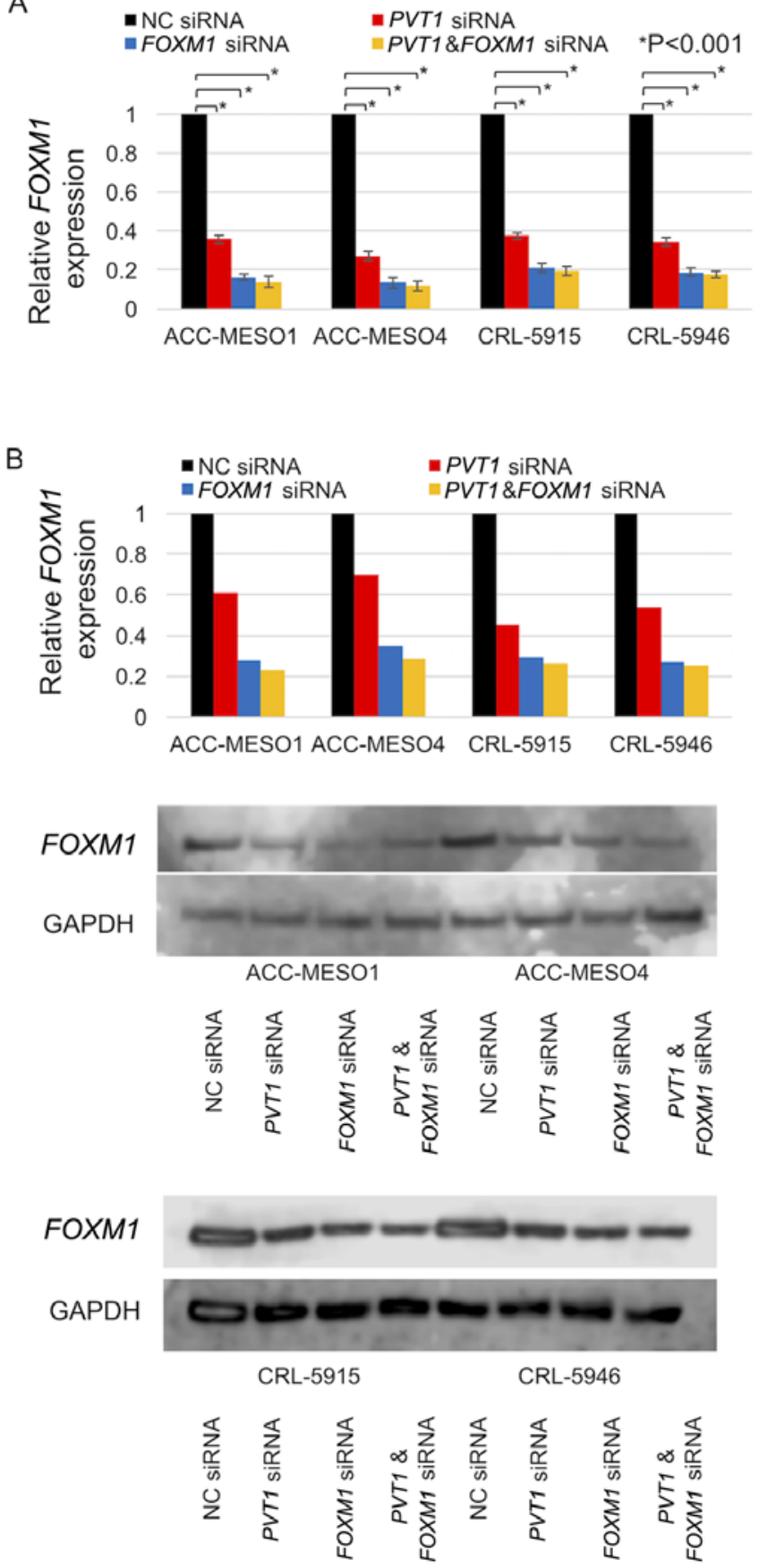

Figure 7. (A) FOXM1 expression of PVT1 siRNA, FOXM1 siRNA and combination of both in siRNA-transfected mesothelioma cell lines as determined by reverse transcription-quantitative PCR. (B) FOXM1 expression as determined by western blot analysis in PVTI siRNA, FOXMI siRNA and combination of both in siRNA-transfected mesothelioma cells. FOXM1, Forkhead box M1; PVT1, plasmacytoma variant translocation 1; siRNA, small interfering RNA; NC, negative control.

reduced the viability of ACC-MESO-1, ACC-MESO-4, CRL-5915, and CRL-5946 cells by 24.8, 19.0, 19.2 and 24.4\%, respectively. Furthermore, inhibition of both $P V T 1$ and FOXM1 expression significantly reduced the viability of ACC-MESO-1, ACC-MESO-4, CRL-5915, and CRL-5946 cells by 37.9, 35.7, 29.1 and $39.9 \%$, respectively (Fig. 6).

PVT1 and FOXM1 knockdown downregulates FOXMI expression. Downregulation of FOXM1 mRNA expression in cells transfected with combined $P V T 1$ and $F O X M 1$ siRNA compared with cells transfected with NC siRNA $(86,88,80$ and $82 \%$ in ACC-MESO-1, ACC-MESO-4, CRL-5915, and CRL-5946 cell lines, respectively) was markedly lower than that in cells transfected with PVT1 siRNA alone $(64,73$, 62 and $65 \%$ ) but similar to that in cells transfected with FOXM1 siRNA alone $(84,86,79$ and 81\%) (Fig. 7A). Downregulation of $F O X M 1$ protein expression in cells transfected with combined PVT1 and FOXM1 siRNA compared with cells transfected with NC siRNA (77, 72, 74 and $75 \%$ in ACC-MESO-1, ACC-MESO-4, CRL-5915, and CRL-5946 cell lines, respectively) was lower than that in cells transfected with PVT1 siRNA alone (39, 30, 54 and 46\%) but similar to that in cells transfected with FOXM1 siRNA alone (72, 65, 70 and 73\%) (Fig. 7B).

\section{Discussion}

Malignant pleural mesothelioma (MPM) is an aggressive form of cancer. Patients with malignant mesothelioma are treated with surgery, radiotherapy, chemotherapy, and targeted drug therapy. However, the survival rates of MPM patients remain extremely low, with survival ranging from 5 to 13.2 months (29).

In a previous study, the median survival period did not improve beyond 13-29 months with extended pleurectomy/decortication and 12-22 months with extrapleural pneumonectomy (30). Therefore, feasible and effective therapeutic targets need to be identified. In the present study, the biological function of PVT1-FOXM1 was investigated as a possible novel target in malignant mesothelioma.

As they regulate gene expression and function at the transcriptional, translational, and post-translational levels, lncRNAs are important in tumor growth and metastasis $(31,32)$. Wright et al have previously revealed various dysregulated lncRNAs involved in the pathogenesis of malignant mesothelioma using NCode long noncoding microarrays and their potential to serve as biomarkers in MPM (33). However, the mechanisms of these lncRNAs have not yet been described in detail. Non-coding transcripts from our previous gene expression microarray analysis of malignant mesothelioma and lung adenocarcinoma were extracted and analyzed and numerous upregulated lncRNAs were identified, including PVT1, MEG3, and H19 (24). Riquelme et al previously suggested that c-Myc and $P V T 1$ copy number gain may promote a malignant phenotype of mesothelioma with PVT1, demonstrating a tendency to upregulate proliferation and inhibit apoptosis (34). The biological functions of PVT1 in malignant mesothelioma have not been fully established; however, previous studies have revealed that $P V T 1$ knockdown inhibits cell proliferation and induces apoptosis through suppression of c-Myc in leukemia (19) and breast cancer (22). PVT1 binds competitively with microRNA-424, which has been reported to increase radiosensitivity by regulating CARM1 in non-small cell lung cancer (18). PVT1 led to increased proliferation and invasion of glioma (35) and hepatocellular carcinoma (20) by targeting EZH2. In the present study, increased expression of PVT1 in mesothelioma and lung adenocarcinoma cell lines was revealed by RT-qPCR, and PVT expression was revealed to be $\sim 2$ times higher in mesothelioma than in lung 
adenocarcinoma cell lines. PVT1 knockdown of mesothelioma cell lines revealed reduced cell proliferation with G2/M arrest and migration.

FOXM1, a member of the FOX transcription factor family 1, is associated to cell viability and is considered a key gene in the carcinogenic pathway. Previous studies have indicated that FOXM1 participates in drug resistance, cancer, and metastasis of cancers (36-38). Several previous studies have demonstrated that FOXM1 is overexpressed in multiple cancers, such as ovarian (39), colon (40), gastrointestinal (41), and non-small cell lung cancer (42). Increased FOXM1 expression was also observed in mesothelioma cell lines, and knockdown of mesothelioma cell lines decreased their proliferation.

$P V T 1$ was revealed to promote tumor progression by interacting with FOXM1 in ovarian and gastric cancer $(43,44)$. In the present study, it was also revealed that $P V T 1$ knockdown in mesothelioma cell lines downregulated FOXM1 expression.

Our study also revealed that $P V T 1$ knockdown reduced FOXM1 expression. Furthermore, knockdown of both FOXM1 and PVT1 in mesothelioma cell lines demonstrated more reduced proliferation of mesothelioma cell lines compared with knockdown of PVT1 or FOXM1 alone. $F O X M 1$ expression in mesothelioma cell lines with combined PVT1 and FOXM1 knockdown was lower than that with PVT1 knockdown alone. Further studies such as spheroid formations and in-vivo experiments which are limited in this study are necessary to clarify the function of PVT1-FOXM1 in mesothelioma cell lines.

In conclusion, it was revealed in the present study that lncRNA $P V T 1$ was upregulated in mesothelioma cell lines, and knockdown of $P V T 1$ decreased the proliferation and migration of mesothelioma cells and downregulated FOXM1 expression. Furthermore, concurrent knockdown of FOXM1 and PVT1 in mesothelioma cell lines demonstrated more reduced proliferation compared with knockdown of $P V T 1$ or FOXM1 alone. $P V T 1$ and FOXM1 may be considered as candidate targets for the therapy of malignant mesothelioma.

\section{Acknowledgements}

The authors would like to thank Ms Yukari Go and Mr Tatsuya Nakagawa of the Technical Center, Hiroshima University for their excellent technical assistance and Ms Naomi Fukuhara (Department of Pathology, Hiroshima University) for administrative support.

\section{Funding}

This research received no specific grant from any funding agency in the public, commercial, or not-for-profit sectors.

\section{Availability of data and materials}

The datasets used and/or analyzed during the current study are available from the corresponding author on reasonable request.

\section{Authors' contributions}

YF, VJA and YT designed the study. VJA and YT supervised and facilitated the study. YF, RS, KK, YK and TK performed the experiments. YF and VJA confirm the authenticity of all the raw data. YF analyzed the data. YF and VJA interpreted the results, and YF wrote the manuscript. All authors read and approved the final version of the manuscript.

\section{Ethics approval and consent to participate}

Not applicable.

\section{Patient consent for publication}

Not applicable.

\section{Competing interests}

The authors declare that they have no competing interests.

\section{References}

1. Frost G: The latency period of mesothelioma among a cohort of British asbestos workers (1978-2005). Br J Cancer 109: 1965-1973, 2013

2. Delgermaa V, Takahashi K, Park EK, Le GV, Hara T and Sorahan T: Global mesothelioma deaths reported to the World Health Organization between 1994 and 2008. Bull World Health Organ 89: 716-724, 724A-724C, 2011.

3. Murayama T, Takahashi K, Natori Y and Kurumatani N: Estimation of future mortality from pleural malignant mesothelioma in Japan based on an age-cohort model. Am J Ind Med 49: 1-7, 2006.

4. Joshi TK and Gupta RK: Asbestos in developing countries: Magnitude of risk and its practical implications. Int J Occup Med Environ Health 17: 179-185, 2004.

5. Yap TA, Aerts JG, Popat S and Fennell DA: Novel insights into mesothelioma biology and implications for therapy. Nat Rev Cancer 17: 475-488, 2017.

6. Ponting CP, Oliver PL and Reik W: Evolution and functions of long noncoding RNAs. Cell 136: 629-641, 2009.

7. Mattick JS: The genetic signatures of noncoding RNAs. PLoS Genet 5: e1000459, 2009.

8. Kapranov P, St Laurent G, Raz T, Ozsolak F, Reynolds CP Sorensen PH, Reaman G, Milos P, Arceci RJ, Thompson JF, et al: The majority of total nuclear-encoded non-ribosomal RNA in a human cell is 'dark matter' un-annotated RNA. BMC Biol 8: 149, 2010.

9. Gibb EA, Brown CJ and Lam WL: The functional role of long non-coding RNA in human carcinomas. Mol Cancer 10: 38, 2011.

10. Gibb EA, Vucic EA, Enfield KS, Stewart GL, Lonergan KM, Kennett JY, Becker-Santos DD, MacAulay CE, Lam S, Brown CJ, et al: Human cancer long non-coding RNA transcriptomes. PLoS One 6: e25915, 2011.

11. Brosnan CA and Voinnet O: The long and the short of noncoding RNAs. Curr Opin Cell Biol 21: 416-425, 2009.

12. Mercer TR, Dinger ME and Mattick JS: Long non-coding RNAs: Insights into functions. Nat Rev Genet 10: 155-159, 2009.

13. Statello L, Guo CJ, Chen LL and Huarte M: Gene regulation by long non-coding RNAs and its biological functions. Nat Rev Mol Cell Biol 22: 96-118, 2021.

14. Guttman M, Amit I, Garber M, French C, Lin MF, Feldser D, Huarte M, Zuk O, Carey BW, Cassady JP, et al: Chromatin signature reveals over a thousand highly conserved large non-coding RNAs in mammals. Nature 458: 223-227, 2009.

15. Costa FF: Non-coding RNAs: Meet thy masters. BioEssays 32: 599-608, 2010.

16. Huarte M and Rinn JL: Large non-coding RNAs: Missing links in cancer? Hum Mol Genet 19: R152-R161, 2010.

17. Cui M, You L, Ren X, Zhao W, Liao Q and Zhao Y: Long non-coding RNA PVT1 and cancer. Biochem Biophys Res Commun 471: 10-14, 2016.

18. Wang D and Hu Y: Long Non-coding RNA PVT1 Competitively Binds MicroRNA-424-5p to Regulate CARM1 in Radiosensitivity of Non-Small-Cell Lung Cancer. Mol Ther Nucleic Acids 16: 130-140, 2019. 
19. Hu J, Han Q, Gu Y, Ma J, McGrath M, Qiao F, Chen B, Song C and Ge Z: Circular RNA PVT1 expression and its roles in acute lymphoblastic leukemia. Epigenomics 10: 723-732, 2018.

20. Guo J, Hao C, Wang C and Li L: Long noncoding RNA PVTI modulates hepatocellular carcinoma cell proliferation and apoptosis by recruiting EZH2. Cancer Cell Int 18: 98, 2018.

21. Zhang R, Li J, Yan X, Jin K, Li W, Liu X, Zhao J, Shang W and Liu Y: Long Noncoding RNA Plasmacytoma Variant Translocation 1 (PVT1) Promotes Colon Cancer Progression via Endogenous Sponging miR-26b. Med Sci Monit 24: 8685-8692, 2018.

22. Guan Y, Kuo WL, Stilwell JL, Takano H, Lapuk AV, Fridlyand J, Mao JH, Yu M, Miller MA, Santos JL, et al: Amplification of PVT1 contributes to the pathophysiology of ovarian and breast cancer. Clin Cancer Res 13: 5745-5755, 2007.

23. Yang Q, Yu Y, Sun Z and Pan Y: Long non-coding RNA PVTI promotes cell proliferation and invasion through regulating miR-133a in ovarian cancer. Biomed Pharmacother 106: 61-67, 2018.

24. Kuraoka M, Amatya VJ, Kushitani K, Mawas AS, Miyata Y, Okada M, Kishimoto T, Inai K, Nishisaka T, Sueda T, et al: Identification of DAB2 and Intelectin-1 as Novel Positive Immunohistochemical Markers of Epithelioid Mesothelioma by Transcriptome Microarray Analysis for Its Differentiation From Pulmonary Adenocarcinoma. Am J Surg Pathol 41: 1045-1052, 2017.

25. Barretina J, Caponigro G, Stransky N, Venkatesan K, Margolin AA, Kim S, Wilson CJ, Lehár J, Kryukov GV, Sonkin D, et al: The Cancer Cell Line Encyclopedia enables predictive modelling of anticancer drug sensitivity. Erratum in: Nature 492: 290, 2012.

26. Livak KJ and Schmittgen TD: Analysis of relative gene expression data using real-time quantitative PCR and the $2(-\Delta \Delta$ C(T)) Method. Methods 25: 402-408, 2001.

27. Gebäck T, Schulz MM, Koumoutsakos P and Detmar M: TScratch: A novel and simple software tool for automated analysis of monolayer wound healing assays. Biotechniques 46 265-274, 2009.

28. Lamprecht MR, Sabatini DM and Carpenter AE: CellProfiler: Free, versatile software for automated biological image analysis. Biotechniques 42: 71-75, 2007.

29. Montanaro F, Rosato R, Gangemi M, Roberti S, Ricceri F, Merler E, Gennaro V, Romanelli A, Chellini E, Pascucci C, et al: Survival of pleural malignant mesothelioma in Italy: A population-based study. Int J Cancer 124: 201-207, 2009.

30. Cao C, Tian D, Park J, Allan J, Pataky KA and Yan TD: A systematic review and meta-analysis of surgical treatments for malignant pleural mesothelioma. Lung Cancer 83: 240-245, 2014.

31. Bunch H: Gene regulation of mammalian long non-coding RNA. Mol Genet Genomics 293: 1-15, 2018

32. Chi Y, Wang D, Wang J, Yu W and Yang J: Long Non-Coding RNA in the Pathogenesis of Cancers. Cells 8: 1015, 2019.
33. Wright CM, Kirschner MB, Cheng YY, O'Byrne KJ, Gray SG, Schelch K, Hoda MA, Klebe S, McCaughan B, van Zandwijk N, et al: Long non coding RNAs (lncRNAs) are dysregulated in Malignant Pleural Mesothelioma (MPM). PLoS One 8: e70940, 2013.

34. Riquelme E, Suraokar MB, Rodriguez J, Mino B, Lin HY, Rice DC, Tsao A and Wistuba II: Frequent coamplification and cooperation between C-MYC and PVT1 oncogenes promote malignant pleural mesothelioma. J Thorac Oncol 9: 998-1007, 2014.

35. Yang A, Wang $\mathrm{H}$ and Yang X: Long non-coding RNA PVT1 indicates a poor prognosis of glioma and promotes cell proliferation and invasion via target EZH2. Biosci Rep 37: BSR20170871, 2017.

36. Fei BY, He X, Ma J, Zhang M and Chai R: FOXM1 is associated with metastasis in colorectal cancer through induction of the epithelial-mesenchymal transition. Oncol Lett 14: 6553-6561, 2017.

37. Shi C and Zhang Z: MicroRNA-320 suppresses cervical cancer cell viability, migration and invasion via directly targeting FOXM1. Oncol Lett 14: 3809-3816, 2017.

38. Zhang J, Chen XY, Huang KJ, Wu WD, Jiang T, Cao J, Zhou LS, Qiu ZJ and Huang C: Expression of FOXMI and the EMT-associated protein E-cadherin in gastric cancer and its clinical significance. Oncol Lett 12: 2445-2450, 2016.

39. Tassi RA, Todeschini P, Siegel ER, Calza S, Cappella P, Ardighieri L, Cadei M, Bugatti M, Romani C, Bandiera E, et al: FOXM1 expression is significantly associated with chemotherapy resistance and adverse prognosis in non-serous epithelial ovarian cancer patients. J Exp Clin Cancer Res 36: 63, 2017.

40. Zhang H, Zhong H, Li L, Ji W and Zhang X: Overexpressed transcription factor $F O X M 1$ contributes to the progression of colorectal cancer. Mol Med Rep 13: 2696-2700, 2016.

41. Zhang J, Niu Y and Huang C: Role of FOXM1 in the Progression and Epithelial to Mesenchymal Transition of Gastrointestinal Cancer. Recent Patents Anticancer Drug Discov 12: 247-259, 2017.

42. Kong FF, Qu ZQ, Yuan HH, Wang JY, Zhao M, Guo YH, Shi J, Gong XD, Zhu YL, Liu F, et al: Overexpression of FOXMI is associated with EMT and is a predictor of poor prognosis in non-small cell lung cancer. Oncol Rep 31: 2660-2668, 2014.

43. Li M, Chi C, Zhou L, Chen Y and Tang X: Circular PVT I regulates cell proliferation and invasion via miR-149-5p/FOXMI axis in ovarian cancer. J Cancer 12: 611-621, 2021.

44. Xu MD, Wang Y, Weng W, Wei P, Qi P, Zhang Q, Tan C, Ni SJ, Dong L, Yang Y, et al: A Positive Feedback Loop of lncRNA-PVT1 and FOXM1 Facilitates Gastric Cancer Growth and Invasion. Clin Cancer Res 23: 2071-2080, 2017.

This work is licensed under a Creative Commons Attribution-NonCommercial-NoDerivatives 4.0 International (CC BY-NC-ND 4.0) License. 